This item was submitted to Loughborough's Research Repository by the author.

Items in Figshare are protected by copyright, with all rights reserved, unless otherwise indicated.

\title{
The extended theory of planned behavior considering heterogeneity under a connected vehicle environment: A case of uncontrolled non-signalized intersections
}

\section{PLEASE CITE THE PUBLISHED VERSION}

https://doi.org/10.1016/j.aap.2020.105934

\section{PUBLISHER}

Elsevier

\section{VERSION}

AM (Accepted Manuscript)

\section{PUBLISHER STATEMENT}

This paper was accepted for publication in the journal Accident Analysis and Preventions and the definitive published version is available at https://doi.org/10.1016/j.aap.2020.105934

\section{LICENCE}

CC BY-NC-ND 4.0

\section{REPOSITORY RECORD}

Zhao, Wenjing, Mohammed Quddus, Helai Huang, Qianshan Jiang, Kui Yang, and Zhongxiang Feng. 2021. "The Extended Theory of Planned Behavior Considering Heterogeneity Under a Connected Vehicle Environment: A Case of Uncontrolled Non-signalized Intersections". Loughborough University. 


\title{
The extended theory of planned behavior considering heterogeneity under a connected vehicle environment: A case of non-signalized intersections
}

\author{
Wenjing ZHAO ${ }^{1}$, Mohammed QUDDUS'2 , Helai HUANG ${ }^{1 *}$, Qianshan JIANG ${ }^{1}$, Kui YANG ${ }^{3}$, Zhongxiang FENG ${ }^{4}$ \\ ${ }^{1}$ School of Traffic and Transportation Engineering, Central South University, Changsha 410000, \\ China. \\ ${ }^{2}$ School of Architecture, Building and Civil Engineering, Loughborough University, Loughborough \\ LE113TU, United Kingdom. \\ ${ }^{3}$ Chair of Transportation Systems Engineering, Department of Civil, Geo and Environmental \\ Engineering, Technical University of Munich, Munich, 85748, Germany. \\ ${ }^{4}$ School of Automobile and Traffic Engineering, Hefei University of Technology, Hefei 230009, China \\ "Correspondence: huanghelai@csu.edu.cn; Tel: +86-18684875075
}

Abstract: Background: With the emergent of connected vehicle (CV) technology, there is a doubt whether CVs can improve driver intentions and behaviors, and thus protect them from accidents with the provision of real-time information. Objective: In order to understand the possible impacts of real-time information provided by $\mathrm{CV}$ technology on drivers, this paper aims to develop a model which considers the heterogeneity between drivers in the extended theory of planned behavior (H-ETPB) in such a situation. Taking a non-signalized intersection as an example, this model examines the relationships between subjective norms, attitudes, risk perceptions, perceived behavioral control and driving intentions, and study how such driving intentions are simultaneously related to by driver characteristics and experiences in the CV environment. Methods: A questionnaire was conducted to build the dataset consisting of 1,001 drivers and then analyzed using a hybrid model integrating a structural equation model (SEM) with a multiple indicators multiple cause model (MIMIC). Findings: Four key findings are obtained: (1) subjective norms, attitudes, perceived behavioral control have directly positive relationships with driving intention to accelerate through a non-signalized intersection with respect to receiving real-time information provided by CV technology; (2) attitudes have a indirectly positive association with driving intentions to accelerate through the perceived behavioral control in such a situation, while risk perceptions have a indirectly negative relationship with their intentions to accelerate through their attitude and perceived behavioral control; (3) driving intentions are significantly affected by employment status, annual driving mileage, and accident involvements in the last three years in such a situation; (4)Furthermore, the attitudes of drivers who occupy a stable salaried job have an indirectly positive relationships with driving intention to accelerate in such a situation, while high risk perceptions of drivers who are stable salaried employees have a indirectly negative association through their perceived behavioral control. Implications: The findings of this study could provide the theoretical framework to optimize traffic performance and information design, as well as provide in-vehicle personalized information service for different drivers in the CV and CAV environment and assist traffic authorities to design the most acceptable traffic rules for different drivers at a non-signalized intersection.

Keywords: connected vehicle (CV), non-signalized intersections, theory of planned behavior (TPB), structural equation model (SEM), multiple indicators multiple cause (MIMIC) model.

\section{Introduction}

Recently, connected vehicle (CV) technology, consisting of vehicle-to-vehicle (V2V), vehicle-to-infrastructure (V2I) and infrastructure-to-vehicle (I2V) wireless communication technologies, has been developing rapidly so as to improve traffic safety and efficiency (e.g., Dey et al., 2016; Shladover, 2018). Several studies related to optimizing traffic organization, designing information and providing personalized information service emerges and gains more attentions along with the development of CV technology. More specifically, some scholars (e.g., Guler et al., 2014; Yang et al. 2019; Ahmed et al., 2019; Liang et al., 2020; Yao et al., 2020) have studied on how to minimize the total delay time and queue length of vehicles, and what types of contents and formats should display for drivers to convince them to follow 
guidance with the provision of real-time information by $\mathrm{CV}$ technology. In addition, how to design the most acceptable real-time information for different drivers has been gradually emphasized. This is because Wang et al., (2012) and Yi et al. (2019) found that the most acceptable information can satisfy driver preferences for information and improve their compliances of information under the $\mathrm{CV}$ environment.

However, whether CV technology is available for traffic safety improvements by optimizing traffic organization and providing relating information service is much dependent on driver awareness of risky situations and their behavior choices. This can be explained by the fact that most accidents caused by drivers who are not aware of the potential hazards and break the traffic rules and make an incorrect decision (Rakha et al., 2007; Takemoto et al., 2008).Awareness of risky situations, as a main factor related to accident occurrence, cannot be directly measured but can be reflected by their driving intentions and behaviors in a specific environment (Ma et al., 2010; Şimşekoğlu et al., 2013; Mohamed and Bromfield, 2017; Cox et al., 2017; Steinbakk et al., 2019). Also, the theory of planned behavior (TPB) and its extension has been usually employed to reflect their awareness of risky situation by explaining and predicting driving intentions and behaviors (Zhou et al., 2009; Ma et al., 2010; Cristea and Delhomme, 2016; Atombo et al., 2016; Cristea and Gheorghiu, 2016; Rowe and Andrews, 2016).

The acceptance and recognitions of real-time information provide by $\mathrm{CV}$ technology varies between drivers (Shin et al., 2015). However, the theory of planned behavior and its extension do not explicitly consider driver different responses to the awareness of risky situations in an unorganized traffic environment. Therefore, this paper aims to fill this knowledge gap by proposing a version of the model, which takes into account the heterogeneity between drivers in the extended theory of planned behavior (H-ETPB) with respect to receiving real-time information in the $\mathrm{CV}$ environment. Taking a non-signalized intersection as an example, this H-ETPB was employed to examine the relationships between subjective norms, attitudes, risk perceptions, perceived behavioral control and driving intentions, and to study how such driving intentions are simultaneously related to driver characteristics and experiences in such a situation. The findings of this study could provide the theoretical framework to optimize traffic performance and information design and in-vehicle personalized information service for different drivers in the $\mathrm{CV}$ and $\mathrm{CAV}$ environment, as well as assist traffic authorities to design the most acceptable traffic rules for different drivers at an intersection.

\section{Literature review}

To propose a new model to consider driver heterogeneity in the extended theory of planned behavior with the provision of real-time information under the $\mathrm{CV}$ environment, this section will review existing related studies related to the influential factors and the analytical methods of behavioral intentions.

\subsection{Factors affecting behavioral intentions and behaviors}

The theory of planned behavior (TPB), as a confirmatory model, has always been used in the explanation and prediction of person's behavioral intentions and behaviors (Ajzen, 1991), especially for aggressive and violated behavioral intentions and behaviors. According to TPB and its extension, driver intentions to behave in a particular manner is predictive of their actual behaviors (Taubman-Ben-Ari et al., 2016; Atombo et al., 2016, 2017a; Jiang et al., 2017; Mohamed and Bromfield, 2017; Wang et al., 2019). This also depends on one's attitudes toward the situation (Chan et al.,2010; Atombo et al.,2016,2017a; Yang et al.,2018; Bordarie, 2019; Wang et al., 2019), risk perceptions (Yang et al., 2018; Gesser-Edelsburg et al.,2018), subjective norms (Conner et al., 2003; Chan et al.,2010; Atombo et al.,2016; Yang et al.,2018; Gesser-Edelsburg et al.,2018; Wang et al., 2019), perceived behavioral control(Conner et al., 2003; Chan et al.,2010; Atombo et al.,2016, 2017a; Bordarie, 2019; Wang et al., 2019), and perceived self-efficacy (Criste and Gheorghiu, 2016; Bordarie, 2019).

Besides, driver characteristics are also found to be a significant factor influencing their behavioral intentions and behaviors. Male drivers have a stronger intention toward drunk and 
offensive behavioral intention than female counterparts (Chan et al., 2010; Varet et al., 2018; Steinbakk et al., 2019), especially for these drivers who are young and feel high social pressures (Marcil et al., 2001; Conner et al., 2003). However, different from these studies, Atombo et al. (2016) found that female drivers are more likely to express the offensive driving intentions, such as speeding and overtaking violations. Nordfjærn et al. (2010) demonstrated that education level significantly affects driver intentions to take a risky driving task. Furthermore, Atombo et al. (2016) found that well-educated drivers are more inclined to intend to have a speeding and overtaking violation. Whitlock et al. (2004) proposed that marital status could significantly influence driver intentions to take a risky driving behavior. Single parent is more likely to intend to take a violated behavior (Mitra-Sarkar and Andreas, 2009; Atombo et al., 2017b). In addition, Atombo et al. (2017b) found that drivers with high socioeconomic status are more likely to intent to speed.

Totally, existing studies concluded that behavioral intentions and behaviors are significantly related to driver subjective norms, attitudes, risk perceptions, perceived behavioral control and driver characteristics. However, these studies do not take into account the differences in relationships between subjective norms, attitudes, risk perceptions, perceived behavioral control, behavioral intentions and behaviors among drivers. Therefore, it is necessary to develop a new model to examine the relationships between TPB variables (i.e., subjective norms, attitudes, risk perceptions, perceived behavioral control, driving intentions and behaviors), and to simultaneously study the association between driver characteristics and experiences and these TPB variables with the provision of real-time information by $\mathrm{CV}$ technology.

\subsection{Research approaches in studying the factors affecting behavioral intentions and behaviors}

The structural equation model (SEM) has been widely employed to analyze the factors affecting behavioral intentions and behaviors, such as pedestrian intentions to cross the road in risky situations (Holland and Hill, 2007), driver intentions to follow the variable speed limit (Hassan and Abdel-Aty, 2011), cyclist intentions to run the red-light (Cristea and Gheorghiu, 2016), driver intentions to violate lane change (Wang et al., 2019). The SEM of these studies includes the measurement model (i.e., confirmatory factor analysis, CFA) and the structural model (i.e., path analysis). These SEM models confirm the relationships between observed indicator variables and latent variables (factors) and directly calculates the measurement errors in the observed indicator variables using its measurement model, and analyze the relationships between latent variables using its structural model. However, the differences of responses to these latent variables between drivers cannot be captured in these models.

The multiple indicators multiple cause (MIMIC) model, expressed as a CFA model with covariates, can solve this problem by exploring the relationships between covariates (such as driver characteristics) and latent variables (factors) (Joreskog and Goldberger, 1975; Teo et al., 2016; Wang and Wang, 2019). As a special SEM, the MIMIC model also consists of the measurement model and the structural model. Similar to the SEM, CFA is also used to examine the relationships between observed indicator variables and the latent variables. However, different from the SEM, the structural model is utilized to analyze the relationships between covariates and latent variables. This means that the MIMIC model can explore the relationships between covariates and latent variables but cannot explain the relationships between different latent variables.

In summary, this paper aims to propose a new model so as to examine the relationships between latent factors, i.e., TPB variables, and to simultaneously study how driver characteristics and experiences relates to these latent factors with respect to receiving real-time alerting information by $\mathrm{CV}$ technology. Hence, the applied model should be satisfied for following requirements: 1) to explain the relationships between latent variables (factors); and 2) to capture the differences of driver responses to these latent variables (factors). To satisfy these two requirements, the structural model of the MIMIC model, as a component, is introduced into the SEM to compensate the limitations of SEM in identifying different 
responses of drivers.

\section{Methodology}

The research methodology consists of a proposed H-ETPB model, a questionnaire survey at a non-signalized intersection, the implementation procedure, a description of the data, and the statistical analysis.

\subsection{A proposed H-ETPB model}

Since the TPB model and its extensions are not capable of fully capturing the differences between drivers with respect to utilizing real-time information under a connected vehicle environment when exploring the relationships between TPB variables, we developed a modified version of TPB model as shown in Figure 1. This modified model considers the heterogeneity between drivers in the extended theory of planned behavior (H-ETPB) by distinguishing their characteristics and experiences. More specifically, this proposed H-ETPB model can examine the relationships between subjective norms, attitudes, risk perceptions, perceived behavioral control, driving intentions and driving behaviors with the provision of real-time information by $\mathrm{CV}$ technology, and simultaneously study the different responses of drivers to these related factors.

Sixteen research hypotheses were proposed in Figure 2. Driving intentions were supposed to be directly associated with by subjective norms $\left(\mathrm{H}_{1}\right)$, attitudes $\left(\mathrm{H}_{2}\right)$, perceived behavioral control $\left(\mathrm{H}_{3}\right)$ with respect to receiving real-time information provided by $\mathrm{CV}$ technology (Cristea and Gheorghiu, 2016; Wang et al., 2019). Referring to Rundmo and Iversen H (2004) and Ma et al. (2010), driver risk perceptions were assumed to directly relate to driving intentions $\left(\mathrm{H}_{4}\right)$ and indirectly relate to their driving intentions through their perceived behavioral control $\left(\mathrm{H}_{5}\right)$ and attitudes $\left(\mathrm{H}_{6}\right)$ in such a situation. According to Cristea and Gheorghiu (2016), driving intentions were indirectly associated with driver attitudes through perceived behavioral control $\left(\mathrm{H}_{7}\right)$ and subjective norm $\left(\mathrm{H}_{8}\right)$ in such a situation. Then, driver subjective norms $\left(\mathrm{H}_{9}\right)$, attitudes $\left(\mathrm{H}_{10}\right)$, risk perceptions $\left(\mathrm{H}_{11}\right)$, perceived behavioral control $\left(\mathrm{H}_{12}\right)$, and driving intentions $\left(\mathrm{H}_{13}\right)$ were supposed to be related to driver characteristics and experiences in such a situation (Rundmo and Iversen H, 2004; Ma et al., 2010; Cestac et al., 2011).

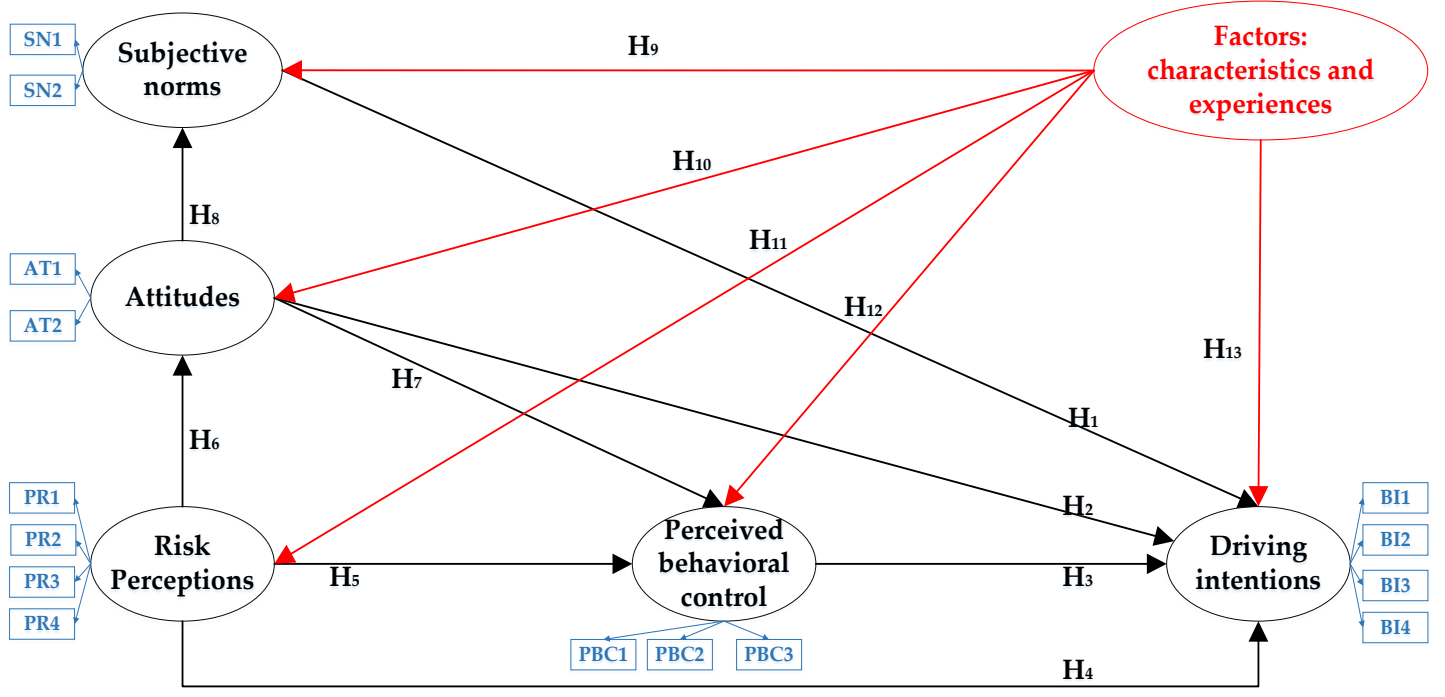

Figure1 H-ETPB model

\subsection{Questionnaire survey at a non-signalized intersection}

To explore the effects of real-time information provided by CV technology on driver awareness for potential hazards, a hypothetical scenario at a non-signalized intersection as an example was employed. Two methods, driving simulators and questionnaire survey, could be 
used to collect the data on driver risky awareness at a non-signalized intersection with respect to receiving real-time information provided by $\mathrm{CV}$ technology. Considering that the limitation of selecting random and large scale samplings as well as simulating the diversity in traffic scenarios of driving simulators, a questionnaire survey was conducted. In this survey, a hypothetical scenario is presented to demonstrate whether drivers intend to accelerate while approaching to a non-signalized intersection when they received real-time information "please slow down" under the CV environment (see Figure 1 with relevant details in Table 1). This information "please slow down" is calculated by the related data, such as peed, distance, acceleration from the vehicles around them, which is collected by CV technology.

More specifically, the design speed, speed limit and the sight distance of main roads and mirror roads connecting the intersection in the scenario referred to the code for planning of intersections on urban roads (GB 506467, 2011). Participants were asked to read the scenario in Figure 2 and related parameters in Table 1, with the statement that "on a two-lane road, you are driving along the main road with a speed of $41 \mathrm{~km} / \mathrm{h}$ and preparing to drive across the nonsignalized intersection 24 meters ahead of you, whilst the in-vehicle system with CV technology informs you to slow down because there is a vehicle without CV technology. The vehicle without $\mathrm{CV}$ technology is approaching to such intersection with $36 \mathrm{~km} / \mathrm{h}$ from the minor road and distancing 40 meters from this intersection". With knowing that the speed limit of main road is $60 \mathrm{~km} / \mathrm{h}$, respondents were asked to answer the questions in Tables 2 and 3.

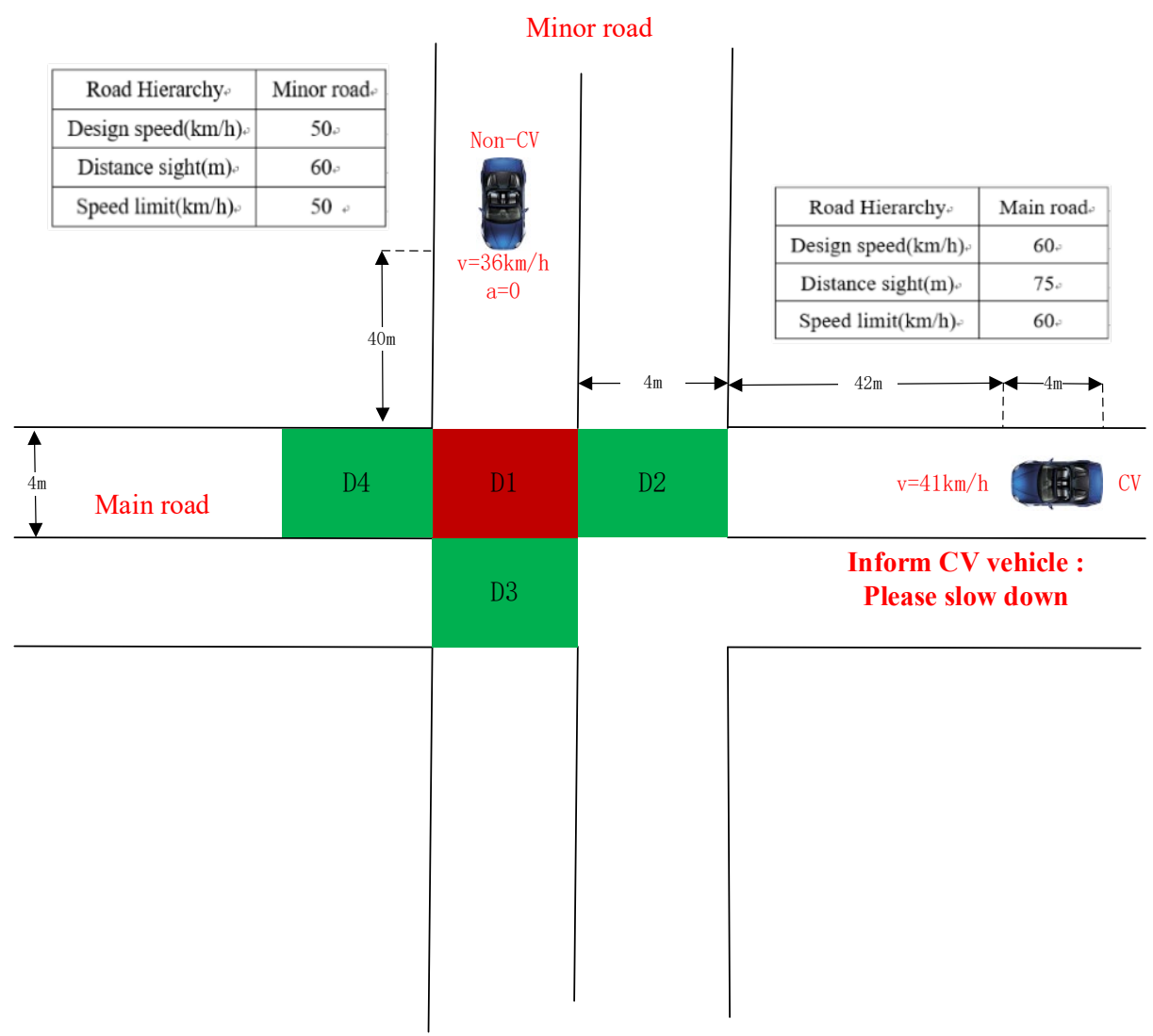


Table 1 Detail description of the scenario

\begin{tabular}{|c|c|c|}
\hline $\begin{array}{l}\text { Driver responses } \\
\text { in main road }\end{array}$ & $\begin{array}{l}\text { Related } \\
\text { parameters }\end{array}$ & Conclusions \\
\hline No change & $\begin{array}{l}\mathrm{T}_{1}=4 \mathrm{~s}, \mathrm{~T}_{3}=4.8 \mathrm{~s} \\
\mathrm{~T}_{2}=4.04, \mathrm{~T}_{4}=4.74\end{array}$ & $\begin{array}{l}\text { The CV vehicle in main road will be involved in crashes without taking } \\
\text { any measures. }\end{array}$ \\
\hline $\begin{array}{l}\text { Constant } \\
\text { acceleration }\end{array}$ & $\begin{array}{l}\mathrm{V}_{\mathrm{a}}=56.5 \mathrm{~km} / \mathrm{h} \\
\mathrm{T}_{4}=4 \mathrm{~s}\end{array}$ & $\begin{array}{l}\text { The CV vehicle in main road can safely go through the } \mathrm{D} 1 \text { and arrives at } \\
\mathrm{D} 4 \text { when this car accelerates to } 56.5 \mathrm{~km} / \mathrm{h} \text { and above, but less than } 60 \mathrm{~km} / \mathrm{h} \text {. }\end{array}$ \\
\hline $\begin{array}{l}\text { Constant } \\
\text { deceleration }\end{array}$ & $\begin{array}{l}\mathrm{V}_{\mathrm{d}}=28 \mathrm{~km} / \mathrm{h} \\
\mathrm{T}_{2}=4.8 \mathrm{~s}\end{array}$ & $\begin{array}{l}\text { The No-CV vehicle in minor road can safely go through the D1 and arrives } \\
\text { at D3, when the vehicle in main road decelerate to } 28 \mathrm{~km} / \mathrm{h} \text { or below in D2. }\end{array}$ \\
\hline $\begin{array}{l}\text { CV vehicle means } \\
\text { Non-CV vehicle } m \\
T_{1} \text { : The time taken } \\
T_{2} \text { : The time taken } \\
T_{3} \text { : The time taken } \\
T_{4} \text { : The time taken } \\
V_{a} \text { : The speed of } t \\
V_{d} \text { : The speed of } t \\
\text { The questic } \\
\text { risk perception } \\
\text { characteristics a } \\
\text { previous studie } \\
\text { definite unlikely } \\
\text { descriptions of }\end{array}$ & $\begin{array}{l}\text { he vehicle install } \\
\text { eans the vehicle } d \\
\text { by the traditional } \\
\text { by the } C V \text { vehicle } \\
\text { by the Non-CV ve } \\
\text { by the } C V \text { vehicle } \\
\text { e CV vehicle on th } \\
\text { e CV vehicle on tl } \\
\text { nnaire include } \\
\text {, perceived } \\
\text { nd experience } \\
\text { as shown in } \\
\text {-very likely, } n\end{array}$ & $\begin{array}{l}\text { nnected vehicle technology; } \\
\text { sn't install connected vehicle technology; } \\
\text { hicle (Non-CV) vehicle in the minor road to arrive at D1; } \\
\text { the main road to arrive at D1; } \\
\text { cle on the minor road to arrive at D3; } \\
\text { the main road to arrive at D4; } \\
\text { main road after a constant acceleration; } \\
\text { main road after a constant deceleration. } \\
\text { two parts: TPB variables, namely subjective norms, attitudes, } \\
\text { havioral control and driving intentions, as well as driver } \\
\text { 15-item describing the TPB variables are stemmed from the } \\
\text { ble } 2 \text {. Each item is measured on a 5-point Likert scale, such as } \\
\text { at all- very much, strongly disagree -strongly agree. The detail } \\
\text { shown in Table } 2 \text {. }\end{array}$ \\
\hline
\end{tabular}




\begin{tabular}{|c|c|c|c|}
\hline Variables & Items & Items & References \\
\hline \multirow{4}{*}{$\begin{array}{l}\text { Driving } \\
\text { intentions }\end{array}$} & BI1 & How likely is it that you would accelerate through a non-signalized intersection as described in the scenario? & \multirow{4}{*}{$\begin{array}{l}\text { Zhou et al. (2009); Hassan and Abdel- } \\
\text { Aty (2011); Cristea and Delhomme } \\
\text { (2016); Cristea and Gheorghiu. (2016) }\end{array}$} \\
\hline & BI2 & How likely is it that you would accelerate through such a non-signalized intersection in the same manner in the near future? & \\
\hline & $\mathrm{BI} 3$ & How much do you expect to accelerate through a non-signalized intersection as described in the scenario? & \\
\hline & BI4 & How much do you expect to accelerate through such a non-signalized intersection in the same manner in the near future? & \\
\hline \multirow{2}{*}{$\begin{array}{l}\text { Subjective } \\
\text { norms }\end{array}$} & SN1 & Your parents, spouse or children would think that you could take a chance to accelerate through such a non-signalized intersection. & \multirow{2}{*}{$\begin{array}{l}\text { Horvath et al. (2012); Cristea and } \\
\text { Gheorghiu (2016); Wang et al.(2019) }\end{array}$} \\
\hline & SN2 & Your friends or colleagues would think that you could take a chance to accelerate through such a non-signalized intersection. & \\
\hline \multirow[t]{2}{*}{ Attitudes } & AT1 & Accelerating through such a non-signalized intersection would get you to your destination more quickly. & \multirow{2}{*}{$\begin{array}{l}\text { Elliott et al. (2007); Zhou et al. (2009); } \\
\text { Horvath et al. (2012); Wang et al.(2019) }\end{array}$} \\
\hline & AT2 & Accelerating through such a non-signalized intersection would be safe and save your time. & \\
\hline \multirow{4}{*}{$\begin{array}{l}\text { Risk } \\
\text { perceptions }\end{array}$} & PR1 & Feeling unsafe that you could be injured in an accident if you accelerate through such a non-signalized intersection. & \multirow{4}{*}{$\begin{array}{l}\text { Rundmo and Iversen H (2004); Ma et } \\
\text { al. ( 2010); Cristea and Delhomme } \\
\text { (2016) }\end{array}$} \\
\hline & PR2 & Feeling unsafe that others could be injured in an accident if you accelerate through such a non-signalized intersection. & \\
\hline & PR3 & Worried for yourself being injured in an accident if you accelerate through such a non-signalized intersection. & \\
\hline & PR4 & Worried for hurting others if you accelerate through such a non-signalized intersection. & \\
\hline \multirow{3}{*}{$\begin{array}{l}\text { Perceived } \\
\text { behavioral } \\
\text { control }\end{array}$} & PBC1 & It is easy for you to control yourself from accelerating through such a non-signalized intersection. & \multirow{3}{*}{$\begin{array}{l}\text { Horvath et al.(2012); Cristea and } \\
\text { Delhomme (2016) ; Wang et al.(2019) }\end{array}$} \\
\hline & $\mathrm{PBC} 2$ & You are confident that you can refrain from accelerating through such a non-signalized intersection. & \\
\hline & $\mathrm{PBC} 3$ & Your capability can match the challenge of the situation when you accelerate through such a non-signalized intersection. & \\
\hline
\end{tabular}


In addition, participants were asked to report their characteristics (e.g. age, gender, employment status, whether joined in the online car hailing services, household structure, education level, and driving age), and experiences (e.g. annual driving mileage, whether being involved in accidents in the last three years and frequencies of crossing non-signalized intersections per week) in Table 3.

Table3 Description of participant characteristics and experiences

\begin{tabular}{|c|c|c|c|}
\hline Variables & Description & Definitions & Percent \\
\hline \multirow[t]{2}{*}{ Gender } & Male & $0 \rightarrow$ Male & $70.03 \%$ \\
\hline & Female & $1 \rightarrow$ Female & $29.97 \%$ \\
\hline \multirow[t]{4}{*}{ Age } & $18-30$ years old & $1 \rightarrow 18-30$ years old & $48.65 \%$ \\
\hline & $31-40$ years old & $2 \rightarrow 31-40$ years old & $32.07 \%$ \\
\hline & $41-50$ years old & $3 \rightarrow 41-50$ years old & $13.99 \%$ \\
\hline & More than 50 years old & $4 \rightarrow$ More than 50 years old & $5.29 \%$ \\
\hline \multirow[t]{2}{*}{ Employment status } & Stable salaried employees & $0 \rightarrow$ Stable salaried employees & $38.56 \%$ \\
\hline & Unstable salaried employees & $1 \rightarrow$ Unstable salaried employers & $61.44 \%$ \\
\hline \multirow{2}{*}{$\begin{array}{l}\text { Whether joined in the online car } \\
\text { hailing services }\end{array}$} & No & $0 \rightarrow \mathrm{No}$ & $85.61 \%$ \\
\hline & Yes & $1 \rightarrow$ Yes & $14.39 \%$ \\
\hline \multirow[t]{3}{*}{ Household structure } & Single-person household & $1 \rightarrow$ Single-person household & $37.46 \%$ \\
\hline & Conjugal family & $2 \rightarrow$ Conjugal family & $7.19 \%$ \\
\hline & Multi-person family & $3 \rightarrow$ Multi-person family & $55.34 \%$ \\
\hline \multirow[t]{5}{*}{ Educational level } & Middle school and below & $1 \rightarrow$ Middle school and below & $2.50 \%$ \\
\hline & High / Polytechnic school & $2 \rightarrow$ High / Polytechnic school & $10.39 \%$ \\
\hline & College & $3 \rightarrow$ College & $16.88 \%$ \\
\hline & Bachelor degree & $4 \rightarrow$ Bachelor degree & $41.76 \%$ \\
\hline & Master degree and above & $5 \rightarrow$ Master degree and above & $28.47 \%$ \\
\hline \multirow[t]{2}{*}{ Driving age } & Less than 6 years & $0 \rightarrow$ Less than 6 years & $64.94 \%$ \\
\hline & More than 6 years & $1 \rightarrow$ More than 6 years & $35.06 \%$ \\
\hline \multirow{4}{*}{$\begin{array}{l}\text { Annual driving } \\
\text { (kilometers) }\end{array}$} & Less than ten thousand & $1 \rightarrow$ Less than ten thousand & $40.06 \%$ \\
\hline & Ten-Thirty thousand & $2 \rightarrow$ Ten-thirty thousand & $39.56 \%$ \\
\hline & Thirty-Fifty thousand & $3 \rightarrow$ Thirty-fifty thousand & $13.79 \%$ \\
\hline & More than fifty thousand & $4 \rightarrow$ More than fifty thousand & $6.59 \%$ \\
\hline \multirow{2}{*}{$\begin{array}{l}\text { Whether being involved in } \\
\text { accidents in the last three years }\end{array}$} & No & $0 \rightarrow \mathrm{No}$ & $40.46 \%$ \\
\hline & Yes & $1 \rightarrow$ Yes & $59.54 \%$ \\
\hline \multirow{3}{*}{$\begin{array}{l}\text { Frequencies of crossing non- } \\
\text { signalized intersections per } \\
\text { week }\end{array}$} & Less than 2 times & $1 \rightarrow$ Less than 2 times per week & $45.65 \%$ \\
\hline & 2-4 times & $2 \rightarrow 2-4$ times per week & $24.38 \%$ \\
\hline & More than 4 times & $3 \rightarrow$ More than 4 times per week & $29.97 \%$ \\
\hline
\end{tabular}

Notes: stable salary employees, such as government officers, obtain a fixed salary every month.

Unstable salary employees, such as self-employed employers, get rewards according to their performance.

\subsection{Implementation procedure}

During 25-29 September 2019, a pilot survey was first conducted to collect the feedback of participants to improve the quality of questionnaires and the fieldwork then carried out from 15-22 October 2019. The data were collected in two ways: by means of face-to-face interviews, and by an internet survey.

For the face to face survey, the questionnaires were distributed to local drivers who were living in six administrative areas (Wangcheng, Kaifu, Furong, Yuelu, Tianxin, and Yuhua) located in Changsha city, China (See Figure 3). The data of each administrative areas were collected and recorded by five surveyors who stood in busy shopping, gas stations, companies etc., and then approached adult individuals with a valid driving license to ask them to complete the questionnaire. In all, 585 survey forms were completed, of which 518 were usable for analysis after excluding survey data with incomplete and invalid information, giving a valid 
rate of $88.55 \%$.

For the internet survey, a total of 588 completed responses were obtained through the Star Asking Platform. Survey data with invalid information were excluded using the IP address as a filtering mechanism to ensure the participants within six administrative areas of Figure 3 and having a valid driving license and valid responses. 483 available questionnaires were obtained with a valid rate of $82.14 \%$.

Overall, survey data with incomplete and invalid information were excluded, resulting in a total of 1,001 respondents with an $85.34 \%$ effective rate.

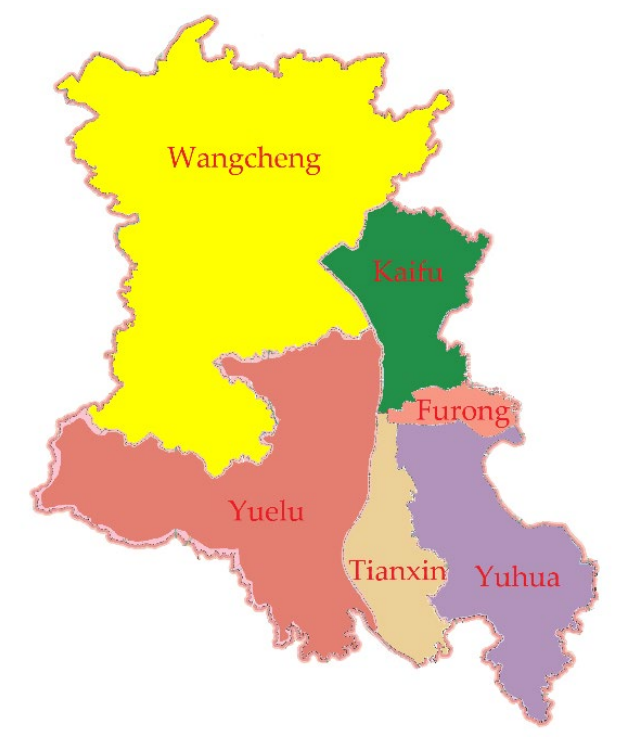

Figure 3 Study area - Changsha, China

\subsection{Data description}

The mean, standard deviation, minimum and maximum of the TPB variables are shown in Table 4. Each item of risk perceptions have a high mean value, while each item of driving intentions, subjective norms, attitudes, and perceived behavioral control have a low mean value. Risky situations may happen with the increasing value of driving intentions, subjective norms, attitudes and perceived behavioral control, and the decreasing value of risk perceptions.

Table 4 Means, standard deviations, minimum and maximum for TPB variables

\begin{tabular}{lccccc}
\hline TPB variables & Items & Mean & SD & Min & Max \\
\hline Driving Intentions & BI1 & 1.59 & 0.84 & 1 & 5 \\
& BI2 & 1.69 & 0.91 & 1 & 5 \\
& BI3 & 1.57 & 0.81 & 1 & 5 \\
Subjective Norms & BI4 & 1.44 & 0.75 & 1 & 5 \\
Attitudes & SN1 & 1.82 & 0.92 & 1 & 5 \\
\multirow{5}{*}{ Risk perceptions } & SN2 & 1.82 & 0.93 & 1 & 5 \\
& AT1 & 1.96 & 0.92 & 1 & 5 \\
& AT2 & 1.93 & 1.01 & 1 & 5 \\
Perceived & PR1 & 4.15 & 0.84 & 1 & 5 \\
behavioral Control & PR2 & 4.14 & 0.78 & 1 & 5 \\
& PR3 & 4.11 & 0.87 & 1 & 5 \\
& PR4 & 3.65 & 1.08 & 1 & 5 \\
& PBC1 & 2.19 & 1.13 & 1 & 5 \\
\hline
\end{tabular}

Besides, the data description of characteristics and experiences of 1,001 participants is 
shown in Table 3. $70.03 \%$ of respondents are male drivers and $85.61 \%$ of respondents have joined in the online car hailing services. Over half of respondents had accident history over the last three years and occupy an unstable salaried job and go across non-signalized intersections more than 2 times per week. Drivers aged between 18 and 30 years old have the largest proportion (48.65\%), followed by between 31 and 40 years old (32.07\%). However, drivers travelled more than fifty thousand kilometers per year have the smallest proportion (6.59\%), followed by between thirty and fifty thousand kilometers per year (13.79\%). For further detail information on participant characteristics and experiences, see Table 3.

\subsection{Statistical analysis}

To verify the proposed H-ETPB model in section 3.2, a hybrid model consisting of a structural equation model (SEM) and a multiple indicators multiple cause (MIMIC) model is developed. The hybrid model is employed because the SEM can analyze the relationships between the exogenous latent variables and the endogenous latent variables, and is capable of accommodating measurement errors when exploring the relationships between these latent variables (Ingvardson et al., 2019), whilst the MIMIC model can unravel the associations between covariates (i.e. driver characteristics and experiences) and latent variables (Chen and Jiang, 2019). The combinative model (SEM-MIMIC) consists of three components as follows:

The first component, the measurement model listed in Eq.(1) and Eq.(2), establishes the relationships between observed indicator variables and latent variables. In this paper, confirmatory factor analysis (CFA) is employed to test the degree of the latent variables, namely TPB variables (driving intentions, subjective norms, attitudes, risk perceptions, perceived behavioral control, as shown in Table 2), composited by their corresponding observed indicators variables (See the blue text-the variables within the rectangles in Figure 2).

The second component, the structural model of MIMIC model expressed in Eq.(3) and Eq.(4), reflects the relationships between covariates (e.g. driver characteristics and experience, see Table 3) and latent variables (TPB variables). This component aims to explore how the driver characteristics and experiences relates to TPB variables (See the red text in Figure 2).

The third component, the structural model in Eq.(5), expresses the relationships between exogenous latent variables and endogenous latent variables. Path analysis is applied to explore the relationships between $\mathrm{t}$ subjective norms, attitudes, risk perceptions, and perceived behavioral control and driving intentions (See the black text in Figure 2).

The mathematical model of combinative model (SEM-MIMIC) can be expressed as:

$$
\begin{aligned}
& \boldsymbol{X}_{i}=\boldsymbol{W}_{i} \boldsymbol{\alpha}_{i}+\boldsymbol{\delta} \\
& \boldsymbol{Y}_{j}=\boldsymbol{Z}_{j} \boldsymbol{a}_{j}+\boldsymbol{\varepsilon} \\
& \boldsymbol{W}_{i}=\boldsymbol{S}_{q i} \boldsymbol{\beta}_{q}+\boldsymbol{v} \\
& \boldsymbol{Z}_{j}=\boldsymbol{S}_{k j} \boldsymbol{\beta}_{k}+\boldsymbol{f} \\
& \boldsymbol{Z}_{j}=\boldsymbol{W}_{j} \boldsymbol{\theta}+\boldsymbol{\xi}
\end{aligned}
$$

where $\boldsymbol{X}_{j}$ are the exogenous observed indicator variables of the latent construct $j ; \mathbf{Y}_{j}$ are the endogenous observed indicator variables of the latent construct $j ; \boldsymbol{W}_{i}$ are the exogenous latent variables characterized by construct $i ; Z_{j}$ are the endogenous latent variables characterized by construct $j ; S_{q j}$ and $S_{k j}$ are the observations of covariates $q$ and covariates $k$ that affect construct $i$ and $j$, representing the cause of construct $i$ and $j$, respectively; Measurement terms are expressed as $\delta, \varepsilon, v, f$, and $\xi$ with a normal distribution, while parameters to be estimated are $\boldsymbol{\alpha}_{i}, \boldsymbol{\alpha}_{j}, \boldsymbol{\beta}_{q}, \boldsymbol{\beta}_{k}$, and $\boldsymbol{\theta}$.

\section{Results}

\subsection{Influential factors identification}

\subsubsection{Exploration factor analysis}

Exploration factor analysis was employed to extract and ensure the dimensions of latent 
variables. $\mathrm{KMO}=0.869$ (a good sampling adequacy) and the Bartlett test showed a significance level of $p<0.01$, indicating that the data are suitable for factor analysis. Five items, i.e., driving intentions, subjective norms, attitudes, risk perceptions, perceived behavioral control, are defined due to the factor with an absolute value greater than 0.40 of each item (Field, 2009). The eigenvalues for five factors-driving intentions, subjective norms, attitudes, risk perceptions, perceived behavioral control-were 2.981, 2.070, 2.004, 1.923 and 1.635, respectively. The five factors could explain $19.870 \%, 13.800 \%, 13.363 \%, 12.821 \%$ and $10.898 \%$ of the variation, respectively. The eigenvalues of five factors were greater than 1 and the cumulative variance contribution rate was $70.752 \%$ (More details see Table 5).

Table 5 Results of exploration factor analysis

\begin{tabular}{|c|c|c|c|c|c|}
\hline Construct & Items & $\begin{array}{l}\text { Factor } \\
\text { loading }\end{array}$ & Eigen-values & $\begin{array}{l}\text { Variance } \\
\text { explained (\%) }\end{array}$ & $\begin{array}{l}\text { Cumulative variance } \\
\text { explained (\%) }\end{array}$ \\
\hline \multirow[t]{4}{*}{ Driving intentions } & BI1 & 0.667 & 2.981 & 19.870 & 19.870 \\
\hline & BI2 & 0.825 & & & \\
\hline & BI3 & 0.896 & & & \\
\hline & BI4 & 0.858 & & & \\
\hline \multirow[t]{2}{*}{ Subjective norms } & SN1 & 0.828 & 2.070 & 13.800 & 33.670 \\
\hline & SN2 & 0.803 & & & \\
\hline \multirow[t]{2}{*}{ Attitudes } & AT1 & 0.787 & 2.004 & 13.363 & 47.032 \\
\hline & AT2 & 0.830 & & & \\
\hline \multirow[t]{4}{*}{ Risk perceptions } & PR1 & 0.570 & 1.923 & 12.821 & 59.854 \\
\hline & PR2 & 0.648 & & & \\
\hline & PR3 & 0.675 & & & \\
\hline & PR4 & 0.812 & & & \\
\hline \multirow{3}{*}{$\begin{array}{l}\text { Perceived behavioral } \\
\text { control }\end{array}$} & PBC1 & 0.746 & 1.635 & 10.898 & 70.752 \\
\hline & $\mathrm{PBC} 2$ & 0.768 & & & \\
\hline & РBC3 & 0.793 & & & \\
\hline
\end{tabular}

\subsubsection{Confirmatory factor analysis}

To test the reliability and validity of the relationships between observed indicator variables and latent variables in the H-ETPB model, CFA, a measurement model, is employed using Mplus 8.3. Three indexes, namely Canbrach's alpha $(\alpha)$, construct reliability $(\mathrm{CR})$ and average variance extracted (AVE), are applied to measure the available reliability and validity of the CFA model in Table 6. More specifically, $\alpha$ and CR refer to the reliability of the latent variables or latent construct underlying a set of observed indictor variables, the stronger correlations between items along with the larger of its value. The AVE, as a validity index, reflects the predictive interpretation ability of the observed variables to the latent variables. Table 6 shows the acceptable reliability and validity of driving intentions, subjective norms, attitudes, risk perceptions, and perceived behavioral control as their Cronbach's alphas $(\alpha)$ and CR are above 0.6 (Nunnally, 1978; Bagozzi and Yi, 1988; Miller, 1995; Ma et al, 2010 ), and the AVE is equal or greater than 0.5(Singh and Sharma, 2014, 2016).

Table 6 Results of confirmatory factor analysis

\begin{tabular}{llll}
\hline Construct & $\alpha$ & CR & AVE \\
\hline Driving intentions & 0.87 & 0.88 & 0.65 \\
Subjective norms & 0.65 & 0.66 & 0.50 \\
Attitudes & 0.68 & 0.68 & 0.52 \\
Risk perceptions & 0.77 & 0.81 & 0.53 \\
Perceived behavioral control & 0.75 & 0.77 & 0.53 \\
\hline
\end{tabular}




\subsubsection{Relationship analysis}

The structural model of SEM is employed to analyze the relationships between TPB variables in Table 1, while the structure model of MIMIC is used to explore the associations between driver characteristics and related experiences (covariates, See Table 2) and TPB variables in the H-ETPB model. In selecting the final set of variables, many variables found to be statistically insignificant at the $90 \%$ confidence interval, then these insignificant variables are removed from the final model (a variable was remove if the $p$-value was more than 0.10 ). The estimated results in term of parameter estimates for the main relationships between TRB variables are shown in Table 7, while the associations between driver characteristics and experiences and TPB factors are shown in Table 8.

Table 7 Standardized results of parameters on relationships between subjective norms, attitudes, risk perceptions, perceived behavioral control and driving intentions

\begin{tabular}{lc}
\hline & Estimate \\
\hline Direct effect & $0.12^{* * *}$ \\
Subjective norms- Driving intentions & $0.16^{* * *}$ \\
Attitudes- Driving intentions & $0.51^{* * *}$ \\
Perceived behavioral control- Driving intentions & $0.13^{*}$ \\
- Indirect effect & $-0.32^{* * *}$ \\
Attitudes- Perceived behavioral control- Driving intentions & $-0.68^{* * *}$ \\
Risk perceptions - Perceived behavioral control- Driving intentions & \\
Risk perceptions- Attitudes- Driving intentions &
\end{tabular}

Note: ${ }^{* *}$ and ${ }^{* * *}$ denote the statistical significance at $10 \%, 5 \%, 1 \%$ levels, respectively

As estimated parameters in Table 7, how much and how likely drivers would intend to accelerate through a non-signalized intersection with the provision of information "please slow down" by CV technology, is related to their subjective norms, attitudes and perceived behavioral control, but has no association with their risk perceptions. Hence $\mathrm{H}_{1}, \mathrm{H}_{2}$, and $\mathrm{H}_{3}$ are supported, while $\mathrm{H}_{4}$ is rejected. More specifically, drivers with positive subjective norms (Estimate $=0.12$ ), attitudes (Estimate $=0.16$ ) and high perceived behavioral control (Estimate $=0.51$ ) are inclined to have a strong intention to accelerate in such a situation.

In addition, how much and how likely drivers would intend to accelerate through a nonsignalized intersection when they are informed to slow down in the $\mathrm{CV}$ environment, are indirectly associated with their attitudes and risk perceptions. Positive attitudes (Estimate $=0.13$ ) encourage drivers to accelerate through a non-signalized intersection in such a CV environment by enhancing their perceived behavioral control, supporting $\mathrm{H}_{6}$. Drivers with high unsafe feeling and worry for being injured or hurting others discourage them to have an intention to accelerate in such a situation by developing a negative attitude (Estimate $=-0.32$ ) and weakening their perceived behavioral control (Estimate=-0.68), hence $\mathrm{H}_{7}$ and $\mathrm{H}_{8}$ are supported. Additionally, there is no association between attitudes and subjective norms in such a situation, rejecting $\mathrm{H}_{5}$.

As shown in Table 8, driving intentions to accelerate through a non-signalized intersection with respect to receiving the information "please slow down" provided by CV technology have a significant relationship with driver employment status, and accident history over the last three years, supporting $\mathrm{H}_{13}$. Specifically, drivers who occupy an unstable salaried job (Estimate $=0.07$ ) or have accident history over the last three years (Estimate $=0.06$ ), have a strong desire to accelerate in such a situation.

Driver subjective norms in accelerating at a non-signalized intersection with respect to receiving information "please slow down" under the CV environment are remarkably related to their education level and annual driving mileage, hence $\mathrm{H}_{9}$ is supported. Drivers who obtained a master degree and above (Estimate $=0.08$ ) or travelled ten-thirty thousand kilometers per year (Estimate $=0.10$ ), have a positive subjective norm in such a situation. It means that the 
important people, such as parents, spouse, children, friends, and colleagues, around these drivers with a master degree and above or travelling ten-thirty thousand kilometers per year think them could take a chance to accelerate in such a situation.

Table 8 Standardized results of parameters on associations between driver characteristics and experiences and TPB variables

\begin{tabular}{lll}
\hline Latent variables & Covariates & Estimate \\
\hline Driving intentions & Employment status (Unstable salaries employees) & $0.07^{* *}$ \\
& Whether being involved in accidents in the last three years (Yes) & $0.06^{* *}$ \\
\hline Subjective norms & Education level (Mater degree and above) & $0.08^{*}$ \\
& Annual driving mileage (Ten-Thirty thousand kilometers) & $0.10^{* *}$ \\
\hline Attitudes & Household structure (Conjugal family) & $-0.07^{* *}$ \\
& Household structure (Multi-person family) & $-0.07^{* *}$ \\
& Annual driving mileage (Ten-Thirty thousand kilometers) & $0.07^{*}$ \\
& Annual driving mileage (Thirty-Fifty thousand kilometers) & $0.07^{*}$ \\
\hline Risk perceptions & Frequencies of crossing non-signalized intersections (2-4 times/ week) & $-0.06^{*}$ \\
\hline Age (31-40 years old) & $0.09^{* *}$ \\
& Age (41-50 years old) & $0.08^{* *}$ \\
\hline Perceived & Education level (High / Polytechnic school) & $-0.08^{* *}$ \\
behavioral control & Gender (Female) & $0.06^{* *}$ \\
& Age (31-40 years old) & $0.07^{* *}$
\end{tabular}

Note:*,** and *** denote the statistical significance at 10\%, 5\%, 1\% levels, respectively

Household structure, annual driving mileage, frequencies of crossing non-signalized intersections per week relate to driver attitudes to the situation whether they would accelerate through a non-signalized intersection with respecting to receiving the information "please slow down" provided by CV technology, supporting H10. Drivers who are from conjugal family (Estimate=-0.07) or multi-person family (Estimate=-0.07), or cross the non-signalized intersections 2-4 times per week (Estimate=-0.06), hold a negative attitude to accelerate in such a situation, while drivers with ten-fifty thousand kilometers per year (Estimate $=0.07$, Estimate=0.07) hold a positive attitude.

Age and education level associate with driver risk perceptions if they accelerate though a non-signalized intersection when they are informed to slow down in the CV environment, supporting $\mathrm{H}_{11}$. Drivers aged between 31-50 years old (Estimate=0.09, Estimate=0.08) have a higher unsafe feeling or worry for being injured or hurting others than counterparts aged 1830 years old, while drivers with high /polytechnic school degree (Estimate=-0.08) have a lower risk perception than counterparts with middle school degree and below in such a situation.

Five variables, namely gender, age, household structure, education level, and whether they had accident involvements in the last three years, have remarkable relationship with driver perceived behavioral control at a non-signalized intersection when they are informed to slow down in the CV environment, supporting $\mathrm{H}_{12}$. Female drivers (Estimate=0.06), drivers aged 3140 years old (Estimate $=0.07$ ), coming from conjugal family (Estimate $=0.06$ ), or obtaining master degree or above (Estimate=0.08), have high perceived behavioral control while drivers with accident involvements in the last three years (Estimate=-0.06) have low perceived behavioral control in such a situation.

In summary, the test results of thirteen hypothesis $\left(\mathrm{H}_{1}-\mathrm{H}_{13}\right)$ in the proposed H-ETPB model as shown in Figure 2 are summarized in Table 9. 


\begin{tabular}{|c|c|}
\hline Items & Results \\
\hline $\mathrm{H}_{1}$ : subjective norms $\rightarrow$ driving intentions & Support \\
\hline $\mathrm{H}_{2}$ : attitudes $\rightarrow$ driving intentions & Support \\
\hline $\mathrm{H}_{3}$ : perceived behavioral control $\rightarrow$ driving intentions & Support \\
\hline $\mathrm{H}_{4}$ : risk perceptions $\rightarrow$ driving intentions & Reject \\
\hline $\mathrm{H}_{5}:$ attitudes $\rightarrow$ subjective norms $\rightarrow$ driving intentions & Reject \\
\hline $\mathrm{H}_{6}$ attitudes $\rightarrow$ perceived behavioral control $\rightarrow$ driving intentions & Support \\
\hline H7: risk perceptions $\rightarrow$ attitudes $\rightarrow$ driving intentions & Support \\
\hline H8: risk perceptions $\rightarrow$ perceived behavioral control $\rightarrow$ driving intentions & Support \\
\hline H9: driver characteristics and experiences $\rightarrow$ subjective norms & Support \\
\hline $\mathrm{H}_{10}:$ driver characteristics and experiences $\rightarrow$ attitudes & Support \\
\hline H11: driver characteristics and experiences $\rightarrow$ risk perceptions & Support \\
\hline $\mathrm{H}_{12}$ : driver characteristics and experiences $\rightarrow$ perceived behavioral control & Support \\
\hline $\mathrm{H}_{13:}$ driver characteristics and experiences $\rightarrow$ driving intentions & Support \\
\hline
\end{tabular}

\subsubsection{Model evaluation and results}

Four fitness indexes, namely Chi-square with degrees of freedom $\left(\chi^{2} / d f\right)$, Root Mean Square Error of Approximation (RMSEA), Goodness of Fit Index (GFI), and Tucker- Lewis index (TLI)(It is also called the Non-Normed Fit Index by Bentler and Bonett (1980) , NNFI), are employed to evaluate a hybrid model (SEM-MIMIC)which is used to verify the proposed H-ETPB model in Table 10. From Table 10, the value of $\chi^{2} / d f$ varies between 1 and 3 , indicating a good model fit (Zhou et al., 2016; Jiang et al., 2019; Wang et al., 2019). Additionally, the values are greater than 0.9 on CFI and TLI (NNFI), as well as smaller than 0.05 on RMSEA, indicative of a good fit (Bentler and Bonett, 1980; Lee et al., 2008; Ma et al., 2010; Hassan and Abdel-Aty, 2011).

Table 10 Fitness indexes for the combinative model (SEM-MIMIC)

\begin{tabular}{lllll}
\hline Fit index & $\chi^{2} / d f$ & RMSEA & GFI & TLI(NNFI) \\
\hline Measured value & 2.956 & 0.044 & 0.922 & 0.910 \\
\hline
\end{tabular}

\subsection{Group-specific differences analysis in driving intentions}

To further verify the appropriateness of the H-ETPB model, we classify drivers into several groups which are homogenous with respect to driver characteristics and experiences and then explore the different factors affecting driving intentions between drivers groups. As the results obtained in Section 4.1, driving intentions to accelerate in the hypothetical scenario are related to driver employment status and accident involvements in the last three years. Hence, the whole sample was reclassified into four groups (See Table 11): (i) group 1: "drivers who are stable salaried employees and not involved in accidents in the last three years"; (ii) group 2: "drivers who are stable salaried employees and involved in accidents in the last three years"; (iii) group 3: "drivers who are unstable salaried employees and not involved in accidents in the last three years"; (iv) group 4: "drivers who are unstable salaried employees and involved in accidents in the last three years".

Table11 Descriptions of four groups

\begin{tabular}{lcl}
\hline Name & Sizes & Descriptions \\
\hline Group 1 & 100 & Drivers who are stable salaried employees and not involved in accidences in the last three years \\
Group 2 & 263 & Drivers who are stable salaried employees and involved in accidences in the last three years \\
Group 3 & 305 & Drivers who are unstable salaried employees and not involved in accidences in the last three years \\
Group 4 & 333 & Drivers who are unstable salaried employees and involved in accidences in the last three years \\
\hline
\end{tabular}

As the four groups described in Table 11, the minimum sample size is 100. According to Tinsley and Tinsley, (1987) and Wang and Wang (2019), 100 samples are available to conduct a 
structural equation model. Hence, four hybrid models (SEM-MIMIC) are employed to identify the factors relating to driving intentions in the situation how much and how likely drivers would intend to accelerate traveling through a non-signalized intersection with the information "please slow down" in the CV environment for each group, respectively. Four fitness indexes of these four models, including $\chi^{2} / d f$, RMSEA, GFI and TLI (NNFI), are presented in Table 9 where we found that all indexes are acceptable.

Table12 Evaluation indexes of each group

\begin{tabular}{ccccc}
\hline & $\chi^{2} / d f$ & RMSEA & GFI & TLI(NNFI) \\
\hline Group 1 & 1.132 & 0.036 & 0.981 & 0.977 \\
Group 2 & 1.470 & 0.042 & 0.970 & 0.964 \\
Group 3 & 1.366 & 0.041 & 0.950 & 0.942 \\
Group 4 & 1.341 & 0.032 & 0.974 & 0.969 \\
\hline
\end{tabular}

The parameter estimates with respect to the relationships between subjective norms, attitudes, risk perceptions, perceived behavioral control and driving intentions of each group are shown in Table 13. The parameter estimates in term of the associations between driver characteristics and experiences and these TPB factors are presented in Table 14. In both tables, each column represents a parameter estimate of each group, significant at $90 \%$ level.

Table13 Standardized results of parameters on relationships between subjective norms, attitudes, risk perceptions, perceived behavioral control and driving intentions of each group

\begin{tabular}{|c|c|c|c|c|}
\hline & Group1 & Group2 & Group3 & Group4 \\
\hline & Estimate & Estimate & Estimate & Estimate \\
\hline \multicolumn{5}{|l|}{ Direct effect } \\
\hline Attitudes- Driving intentions & - & $0.17^{* * *}$ & $0.25^{* * *}$ & $0.15^{* * *}$ \\
\hline Perceived behavioral control- Driving intentions & $0.32^{* * *}$ & $0.62^{* * *}$ & $0.39^{* * * *}$ & $0.58^{* * *}$ \\
\hline \multicolumn{5}{|l|}{ Indirect effect } \\
\hline Attitudes- Perceived behavioral control- Driving intentions & - & - & $0.45^{* * *}$ & $0.36^{* * *}$ \\
\hline Risk perceptions - Perceived behavioral control- Driving intentions & $-0.43^{* * *}$ & $-0.46^{* * *}$ & - & - \\
\hline Risk perceptions- Attitudes- Driving intentions & - & $-0.74^{* * *}$ & $-0.73^{* * *}$ & $-0.68^{* * *}$ \\
\hline
\end{tabular}

In Table 13, driving intentions to accelerate through a non-signalized intersection with the provision of information "please slow down" in the CV environment are directly and positively related to driver attitudes and perceived behavioral control in group 2-4 (i.e., drivers who are stable salaried employees and are involved in accidents in the last three years, as well as drivers who are unstable salaried employees). However, driving intentions in such a situation is only directly associated with driver perceived behavioral control in group 1 (drivers who are stable salaried employees and have accident involvements in the last three years).

Regarding to drivers who have a stable salaried occupation (group 3 and 4), positive attitudes make them incline to accelerate through a non-signalized intersection even though $\mathrm{CV}$ technology informs them to slow down by enhancing their perceived behavioral control, while these drivers with high risk perceptions are unwilling to accelerate by developing a negative attitude. Drivers in group 1-2 (drivers who are stable salaried employees) with high risk perceptions have a low intention to accelerate in such a situation by weakening their perceived behavioral control in group 1-2. Also, drivers in group 2 with high risk perceptions are indirectly related to driving intentions by generating a negative attitude in such a situation. 
Table 14 Standardized results of parameters on associations between driver characteristics and experiences and TPB variables

\begin{tabular}{|c|c|c|c|c|c|}
\hline \multirow{2}{*}{$\begin{array}{l}\text { Latent } \\
\text { variables }\end{array}$} & \multirow[t]{2}{*}{ Driver characteristics and experiences (Covariates) } & Group1 & Group2 & Group3 & Group4 \\
\hline & & Estimate & Estimate & Estimate & Estimate \\
\hline \multirow[t]{7}{*}{ Attitudes } & Annual driving mileage (Ten-Thirty thousand kilometers) & - & - & - & $0.10^{*}$ \\
\hline & Annual driving mileage (Thirty-Fifty thousand kilometers) & - & - & $0.13^{* *}$ & - \\
\hline & Annual driving mileage (More than fifty thousand kilometers) & - & - & - & $0.11^{* *}$ \\
\hline & Education level (High / Polytechnic school) & - & - & $-0.11^{*}$ & - \\
\hline & Household structure (Conjugal family) & - & - & $-0.10^{*}$ & - \\
\hline & Household structure (Multi-person family) & - & - & - & $-0.11^{* *}$ \\
\hline & $\begin{array}{l}\text { Frequencies of crossing non-signalized intersections per week } \\
\text { (2-4 times) }\end{array}$ & - & $-0.11^{* *}$ & - & - \\
\hline \multirow{5}{*}{$\begin{array}{l}\text { Risk } \\
\text { perceptions }\end{array}$} & Age (31-40 years old) & - & - & $0.10^{*}$ & $0.10^{*}$ \\
\hline & Whether joined in the online car hailing services (Yes) & - & - & $0.17^{* * *}$ & $0.10^{*}$ \\
\hline & Annual driving mileage (Thirty-fifty thousand kilometers ) & - & - & - & $-0.15^{* * *}$ \\
\hline & Education level (High / Polytechnic school ) & - & $-0.11^{*}$ & - & - \\
\hline & Education level (College ) & - & $-0.18^{* * *}$ & - & - \\
\hline \multirow{8}{*}{$\begin{array}{l}\text { Perceived } \\
\text { behavioral } \\
\text { control }\end{array}$} & Gender(Female) & $0.22^{* *}$ & - & $0.13^{* *}$ & - \\
\hline & Age (31-40 years old) & $0.22^{* *}$ & - & - & - \\
\hline & Household structure (Conjugal family) & - & $-0.11^{*}$ & - & $0.15^{* * *}$ \\
\hline & Household structure (Multi-person family) & $-0.25^{* * *}$ & - & - & - \\
\hline & Driving age (More than 6 years) & - & - & $-0.12^{* *}$ & - \\
\hline & Annual driving mileage (Ten-thirty thousand kilometers ) & $0.20^{* *}$ & - & - & - \\
\hline & Annual driving mileage (More than fifty thousand kilometers ) & - & - & $0.11^{*}$ & - \\
\hline & Education level (Master degree or above) & - & $0.13^{* *}$ & - & $0.11^{* *}$ \\
\hline
\end{tabular}

Note:*** and ${ }^{* * *}$ denote the statistical significance at $10 \%, 5 \%, 1 \%$ levels, respectively

As shown in Table 14, driver perceived behavioral control to accelerate through a nonsignalized intersection with the provision of information "please slow down" in the CV environment is related to their gender, age, driving age and annual driving mileage in the group 1 (drivers who are stable salaried employees and not involved in accidents in the last three years). More specifically, female, 31-40 years old and ten-thirty thousand kilometers per year is positively associated with the perceived behavioral control of these drivers, while multiperson family household structure is negatively associated with in such a situation.

As for drivers who have a stable salaried occupation and accidents involvements in the last three years (group2), their attitudes, risk perceptions and perceived behavioral control are associated with their characteristics and experiences in the situation whether they intend to accelerate through a non-signalized intersection with the provision of information "please slow down" in the CV environment. Crossing non-signalized intersections 2-4 times per week makes these drivers hold a negative attitude in such a situation. Drivers in group 2 with high / polytechnic school degree and college degree are negatively related to their risk perceptions of such a situation. Also, drivers with a master degree or above in this group have high perceived behavioral control, while drivers from conjugal family in this group have low perceived behavioral control in such a situation.

Similar to group 2, driver attitudes, risk perceptions and perceived behavioral control are related to their characteristics and experiences in group3 (drivers who are unstable salaried employees and not involved in accidents in the last three years) in such a situation. These drivers with conjugal family and high/polytechnic school degree show a significantly negative 
association with their attitudes in such a situation, while these drivers with thirty-fifty thousand kilometers per year have a positive association. Drivers aged 31-40 years old or joined in the online car hailing services in this group have a high risk perception in such a situation. Additionally, female drivers or experienced drivers (i.e., drivers with more than fifty thousand kilometers a year) in this group have a positive association with their perceived behavioral control in this situation, while these drivers with more than 6-year driving age have a negative association.

Similar to group 2 and 3, driver attitudes, risk perceptions and perceived behavioral control are also related to their characteristics and experiences in group 4 (drivers who have an unstable salary and accident involvements in the last three years) in such a situation. Drivers in group 4 travelled ten-thirty thousand kilometers per year and more than fifty thousand kilometers per year, positively relates to their attitudes in such a situation, while these drivers from multi-person family hold a negative attitude. In this group, drivers aged 31-40 years old or joined in the online car hailing services have a high risk perception, while drivers with thirtyfifty thousand kilometers per year have a low risk perception in such a situation. Also, welleducated drivers or drivers from conjugal family in group 4 have high perceived behavioral control.

In summary, factors relating to driving intentions vary between four driver groups in the situation where drivers can receive the information "please slow down" under the CV environment. Hence, we can conclude that the H-ETPB model is available for identifying the heterogeneity between drivers on driving intentions in such a situation.

\section{Discussions}

\subsection{Relationships between TPB variables}

Subjective norms, attitudes and perceived behavioral control are found to directly associate with driving intentions to accelerate at a non-signalized intersection with the provision of real-time information by $\mathrm{CV}$ technology, which confirms the previous findings (Elliott et al, 2007; Zhou et al., 2009; Daphne et al., 2010; Atombo et al., 2016; Cristea and Gheorghiu, 2016; Wang et al., 2019). Specifically, drivers with positive subjective norms and attitudes, and high perceived behavioral control, are likely to have a stronger intention to accelerate in such a situation, which is consistent with Zhou et al. (2009). However, driving intentions to accelerate through a non-signalized intersection in such a situation have no relationships with risk perception, which is inconsistent with previous studies (Rundmo and Iversen, 2004; Cristea and Delhomme, 2016). This can be explained by Hagl and Kouabenan (2020), who found that drivers are confident in their driving capability to deal with the unexpected situations with the provision of the real-time information by $\mathrm{CV}$ technology, and therefore they are not worried for being injured or hurting others when they intend to accelerate through such a non-signalized intersection in such an environment.

Attitudes, risk perceptions and perceived behavioral control indirectly relates to driving intentions to accelerate through a non-signalized intersection with respect to receiving alerting information provided by CV technology, which confirms the previous findings(Ma et al., 2010; Cristea and Gheorghiu, 2016; Jiang et al., 2019; Wang et al., 2019). Driver with positive attitudes are likely to intend to accelerate by enhancing their perceived behavioral control, while high risk perceptions are unwilling to have an acceleration by developing a negative attitude and weakening their perceived behavioral control in such a situation, which is consistent with some previous works (Ma et al., 2010; Wang et al., 2019). However, attitudes have no relationship with subjective norms in such a situation, which is inconsistent with previous works conducted by Cristea and Gheorghiu(2016), Wang et al. (2019), who found that there are a significantly positive correlation between attitudes and subjective norms in term of the relationships with driving intentions. One possible explanation is provided by Horvath et al. (2012), who pointed out that drivers think the important people such as parents, spouse, children, friends, and colleagues, around them do not have sufficient recognitions and understanding of one thing, such as CV technology, thus exerted minimal influences on their attitudes. 


\subsection{Effects of driver characteristics and experiences on TPB variables}

Driving intentions to accelerate through a non-signalized intersection with respect to receiving real-time information provided by $\mathrm{CV}$ technology is significantly related to driver employment status, and accident history over the last three years. Drivers with unstable salary are likely to have an intention to accelerate in such a situation because of a high pressure from daily life. Also, drivers with accident history over the last three years are inclined to have an intention to accelerate in such a situation. This can be explained by the fact that these drivers usually overestimate their ability to deal with unexpected situations and underestimate the negative consequences for themselves and others, thus lead to a strong intention to accelerate in such a situation.

Compared with drivers travelling less than ten thousand kilometers per year, drivers travelling ten-thirty thousand kilometers per year have a higher subjective norm at a nonsignalized intersection with respect to receiving real-time information in the CV environment, which is consistent with Cestac et al. (2011), who found that subjective norms increase with high annual driving mileage. Also, high education level positively relates to driver subjective norms in such a situation. A plausible explanation for this fact is that well-educated drivers are easy to obtain a high trust from the important people around them- parents, spouse, children, friends, and colleagues, thus they are expected to take a chance to have an acceleration in such a situation.

Driver attitudes whether they would accelerate through a non-signalized intersection when they received real-time information in the $\mathrm{CV}$ environment, are associated with their household structure, annual driving mileage, and frequencies of crossing non-signalized intersections. Drivers from single family hold a positive attitude to have an acceleration in such a situation than the counterparts from conjugal family and multi-person family. One possible explanation is that these drivers suffer less responsibility and pressure from the family, leading to a positive attitude to enjoy driving simulations. Another explanation is that it is easy for these drivers to develop psychological negative emotion, such as loneness and frustration, which irritates them to hold a positive attitude to accelerate in such a situation (Atombo et al., 2017b). Experienced drivers have a positive attitude in such a situation, which can be explained by Atombo et al. (2016) and Steinbakk et al. (2019), who found that these drivers are confident in dealing with unexpected situations, and then being capable of protecting them from risk situation. Also, 2-4 time crossing non-signalized intersections per week negatively relates to driver attitudes in such a situation. A plausible explanation is that these drivers have a high exposure to such an intersection and well understand the high risks of accelerating in such a situation.

Risk perceptions associate with driver age and education level in the situation where they accelerate through a non-signalized intersection with the provision of real-time information in the $\mathrm{CV}$ environment. Compared with younger drivers, middle-aged drivers have a higher risk perceptions in such a situation, which is consistent with Sivak et al. (1989). This can also be supported by questionnaire data which demonstrated that the mean value of risk perceptions of middle-aged drivers (4.08) is larger than younger counterparts (3.96) in such a situation. Also, drivers with high /polytechnic school degree have a lower risk perception than counterparts with middle school and below, which is inconsistent with Nordfjirn and Rundmo (2009), who found that education level has no relationships with their risk perceptions. This is because drivers with primary school degree as their highest education level were merged together with drivers who had high school as their highest levels of educational achievement by Nordfjrn and Rundmo, failing to reveal this finding.

Perceived behavioral control are found to relate to driver gender, age, household structure, education level and accident involvement in the last three years in the situation where they accelerate through a non-signalized intersection with respect to receiving real-time information provided by CV technology. Middle-aged drivers have a higher perceived behavioral control than younger counterparts in such a situation, which is consistent with Diaz (2002). However, female drivers or drivers with accident history over the last three years have low perceived 
behavioral control in such a situation, which is inconsistent with Diaz (2002), who found that gender and accident history over the last three years have no relationships with driver perceived behavioral control. One possible explanation of these findings is that a small sample size of Diaz (146 samples) fails to reveal the significant relationships between both variables on the perceived behavioral control. Regarding to drivers who had accident history over the last three years, these drivers who have an unstable salaried occupation and conjugal family have high perceived behavioral control, while these drivers who have a stable salaried occupation and conjugal family have low perceived behavioral control. This is supported by the questionnaire data which demonstrated that, regarding to drivers with accident involvements in the last three years, the mean value of perceived perception control of these drivers with a unstable salaried occupation and conjugal family household structure (2.33), is much higher than counterparts with a unstable salaried occupation and a single family household structure (2.00), but the mean value of that of these drivers with a stable salaried occupation and a conjugal family household structure(1.67), is much lower than counterparts with a stable salaried occupation and a single family household structure (2.02). Also, well-educated drivers have high perceived behavioral control in such a situation. One possible explanation of this fact is that these drivers have a strong self-control to follow the information to avoid being involving in risky situations.

\subsection{Limitations and future research}

Certain limitations of this study should be noted. First, drivers who were asked to respond their subjective responses to the hypothetical situation where they are exposed to the real-time information provided by the $\mathrm{CV}$ technology, likely have never experienced the $\mathrm{CV}$ environment before. Second, the empirical data was collected by driver subjective perception of what they would do in the imagining the specific scenario, rather than what they would have done in the laboratory simulation. Thirdly, more scenarios should be considered to test the general applicability of the proposed model- considering the heterogeneity between drivers in the extended theory of planned behavior in the CV environment. Fourthly, the casual relationships and effect of these latent variables cannot be explored due to the limitation of conducting a cross-sectional survey.

In the follow-up studies, a questionnaire survey about how drivers respond to the realtime information provided by the CV technology after the implementation of CV technology, should be collected for comparison. The empirical data about perception of what they would do in the imagining the specific scenario should be collected by laboratory simulation for comparison. More scenarios, such as lane change and overtaking, should be considered to verify the general applicability of the extended theory of planned behavior considering the heterogeneity between drivers in the CV environment. Additionally, we would enlarge the sample and then set $95 \%$ confidence interval as the significance level to explore the relationships between variables in the future work.

\section{Conclusions}

There is a dearth of research on comprehensively considering the heterogeneity between drivers when exploring the relationships between variables in the theory of planned behavior and its extension. The objective of this paper was to propose a version of the TPB model, which considers the heterogeneity of drivers in the extended theory of planned behavior (H-ETPB) with respect to receiving real-time information in the $\mathrm{CV}$ environment. Taking a non-signalized intersection as an example, this H-ETPB model was employed to examine the relationships between subjective norms, attitudes, risk perceptions, perceived behavioral control and driving intentions, and to study how such driving intentions are simultaneously related to driver characteristics and experiences in such a situation. Instead of driving simulator, a questionnaire survey was conducted to cover the problems on random and large scale samplings, and then utilized to verify the proposed H-ETPB model using a hybrid model integrating a structural equation model (SEM) with a multiple indicators multiple cause model (MIMIC).This paper 
makes four contributions:

(1) This proposed H-ETPB model is one of the first to consider the heterogeneity of drivers in the extended theory of planned behavior in the $\mathrm{CV}$ environment. This model was verified by the scenario how much and how likely drivers would have an intention to accelerate a nonsignalized intersection with respect to receiving the information "please slow down" in the CV environment. In addition, a hybrid model integrating structural equation model (SEM) with a multiple indicators multiple cause (MIMIC) was employed to verify of the proposed H-ETPB model with a good fitness in such a situation.

(2) Drivers with positive subjective norms, attitudes and high perceived behavioral control, are likely to have a stronger intention to accelerate through a non-signalized intersection when $\mathrm{CV}$ technology informs them to slow down. Also, positive attitudes indirectly relate to driving intentions to accelerate in such a situation by enhancing the perceived behavioral control. High risk perceptions negatively associate with driving intentions to accelerate in such situation through developing a negative attitude and weakening the perceived behavioral control.

(3) Driver characteristics and experiences significantly relate to driving intentions, subjective norms, attitudes, risk perceptions and perceived behavioral control in the situation where they are informed to slow down at a non-signalized intersection under the $\mathrm{CV}$ environment. Five core findings can be concluded in such a situation: a) drivers who are unstable salaried employees, rich in driving experience and not involved in accidents in the last three years, have a strong intention to accelerate; $b$ ) well-educated drivers have a high subjective norm; c) drivers from single family have a positive attitude, while drivers with accident history over the last three years hold a negative attitude; $d$ ) middle-age drivers have a high risk perception; e) female drivers or drivers with accident involvements in the last three years have low perceived behavioral control.

(4) There are remarkable differences of factors relating to driving intentions between drivers with respect to receiving real-time information a non-signalized intersection under the $\mathrm{CV}$ environment, which further verify the appropriateness of the proposed H-ETPB model. Firstly, driving intentions of four driver subgroups who are homologous with respect to employment status and accident history over the last three years, has a direct and indirect association with to attitudes, risk perceptions and perceived behavioral control, but has no relationship with subjective norms in such a situation. Secondly, female drivers without accident history over the last three years, and well-educated drivers with accident involvements in the last three years, have high perceived behavioral control in such a situation. Thirdly, regarding to drivers who have accident history over the last three years and conjugal family household structure, unstable-salaried drivers have high perceived behavioral control, while stable-salaried drivers have low perceived behavioral control in such a situation. Fourthly, middle-age drivers or unstable-salaried drivers who even joined in the online car hailing services have a high risk perception in such a situation.

\section{Acknowledgements}

This work was jointly supported by: 1) The Joint Research Scheme of National Natural Science Foundation of China/Research Grants Council of Hong Kong (No. 71561167001 \& N_HKU707/15); 2) The National Natural Science Foundation of China (Project No. 71701216); 3) National Key Research and Development Plan (No. 2018YFB1201601).

\section{References}

Ahmed M, Yang G, Gaweesh S. 2019. Assessment of connected vehicle human machine interface using a high-fidelity driving simulator: preliminary findings from the Wyoming connected vehicle pilot deployment program. Transportation Research Board.

Ajzen, I. 1991. The theory of planned behavior. Organizational behavior and human decision processes, 50(2), 179-211.

Atombo, C., Wu, C., Zhong, M., Zhang, H. 2016. Investigating the motivational factors 
influencing driver's intentions to unsafe driving behaviours: Speeding and overtaking violations. Transportation research part F: traffic psychology and behaviour, 43, 104-121.

Atombo, C., Wu, C., Zhang, H., Wemegah, T. D. 2017a. Perceived enjoyment, concentration, intention, and speed violation behavior: Using flow theory and theory of planned behavior. Traffic injury prevention, 18(7), 694-702.

Atombo, C., Wu, C., Tettehfio, E. O., Agbo, A. A., 2017b. Personality, socioeconomic status, attitude, intention and risky driving behavior. Cogent Psychology, 4(1), 1376424.

Bagozzi, R. P., Yi, Y. 1988. On the evaluation of structural equation models. Journal of the academy of marketing science, 16(1), 74-94.

Bentler, P. M., Bonett, D. G. 1980. Significance tests and goodness of fit in the analysis of covariance structures. Psychological Bulletin, 88, 588 - 606.

Bordarie J. 2019. Predicting intentions to comply with speed limits using a 'decision tree' applied to an extended version of the theory of planned behaviour. Transportation research part F: traffic psychology and behaviour, 63: 174-185.

Cestac J, Paran F, Delhomme P. 2011. Young drivers' sensation seeking, subjective norms, and perceived behavioral control and their roles in predicting speeding intention: How risktaking motivations evolve with gender and driving experience. Safety science, 49(3): 424432.

Chan D C N, Wu A M S, Hung E P W., 2010. Invulnerability and the intention to drink and drive: An application of the theory of planned behavior. Accident Analysis and Prevention, 42(6): 1549-1555.

Chen Y, Jiang K. A. 2019. Multiple indicators multiple causes (mimic) model of the behavioral consequences of hotel guests. Tourism management perspectives, 30: 197-207.

Conner, M., Smith, N., McMillan, B. 2003. Examining normative pressure in the theory of planned behaviour: Impact of gender and passengers on intentions to break the speed limit. Current Psychology, 22(3), 252-263.

Cox J A, Beanland V, Filtness A J. 2017. Risk and safety perception on urban and rural roads: Effects of environmental features, driver age and risk sensitivity. Traffic injury prevention, 18(7): 703-710.

Cristea, M., Delhomme, P. 2016. The effects of co-presence on risk perception and intention to engage in risky behaviors. Journal of safety research, 56, 97-103.

Cristea M, Gheorghiu A., 2016. Attitude, perceived behavioral control, and intention to adopt risky behaviors. Transportation research part F: traffic psychology and behaviour, 43: 157-165.

Dey, K.C., A. Rayamaihi, M. Chowdhury, P. Bhavsar, and J. Martin. 2016. Vehicle-to-vehicle $(\mathrm{V} 2 \mathrm{~V})$ and vehicle-to-infrastructure (V2I) communication in a heterogeneous wireless network - Performance evaluation. Transportation Research Part C: Emerging Technologies, 68:168-184.

Diaz E M. 2002.Theory of planned behavior and pedestrians' intentions to violate traffic regulations. Transportation Research Part F: Traffic Psychology and Behaviour, 5(3): 169-175.

Elliott M A, Armitage C J, Baughan C J. 2007. Using the theory of planned behaviour to predict observed driving behaviour. British Journal of Social Psychology, 46(1): 69-90.

Field, A., 2009. Discovering statistics using SPSS, 3rd ed., London. 
GB 506467. 2011. Code for planning of intersection on urban roads. China Planning Press.

Gesser-Edelsburga A., Zemach M., Lotan T., Elias W., Grimberg E., 2018. Perceptions, intentions and behavioral norms that affect pre-license driving among Arab youth in Israel. Accident analysis and prevention, 111:1-11.

Guler, S. I., Menendez, M., Meier, L., 2014. Using connected vehicle technology to improve the efficiency of intersections. Transportation Research Part C: Emerging Technologies, 46, 121-131.

Hagl, M., Kouabenan, D. R. 2020. Safe on the road-Does Advanced Driver-Assistance Systems Use affect Road Risk Perception? Transportation Research Part F: Traffic Psychology and Behaviour, 73, 488-498.

Hassan H M, Abdel-Aty M A. 2011. Analysis of drivers' behavior under reduced visibility conditions using a structural equation modeling approach. Transportation research part F: traffic psychology and behavior, 14(6): 614-625.

Holland C, Hill R. 2007.The effect of age, gender and driver status on pedestrians' intentions to cross the road in risky situations. Accident Analysis and Prevention, 39(2): 224-237.

Horvath, C., Lewis, I., Watson, B. 2012. Peer passenger identity and passenger pressure on young drivers' speeding intentions. Transportation research part F: traffic psychology and behaviour, 15(1), 52-64.

Ingvardson J B, Nielsen O A. 2019. The relationship between norms, satisfaction and public transport use: A comparison across six European cities using structural equation modelling. Transportation research part A: policy and practice, 126: 37-57.

Jiang K, Ling F, Feng Z, Wang K, Shao C. 2017. Why do drivers continue driving while fatigued? An application of the theory of planned behaviour. Transportation Research Part A: Policy and Practice, 98: 141-149.

Jiang, K., Yang, Z., Feng, Z., Yu, Z., Bao, S., Huang, Z. 2019. Mobile phone use while cycling: a study based on the theory of planned behavior. Transportation research part F: traffic psychology and behaviour, 64, 388-400.

Jöreskog K G, Goldberger A S., 1975. Estimation of a model with multiple indicators and multiple causes of a single latent variable. Journal of the American Statistical Association, 70(351a): 631-639.

Lee J Y, Chung J H, Son B. 2008. Analysis of traffic accident size for Korean highway using structural equation models. Accident Analysis and Prevention, 40(6): 1955-1963.

Liang X J, Guler S I, Gayah V V. 2020. An equitable traffic signal control scheme at isolated signalized intersections using Connected Vehicle technology. Transportation Research Part C: Emerging Technologies, 110: 81-97.

Ma, M., Yan, X., Huang, H., Abdel-Aty, M. 2010. Safety of public transportation occupational drivers: Risk perception, attitudes, and driving behavior. Transportation Research Record, 2145(1), 72-79.

Marcil I, Bergeron J, Audet T. 2001. Motivational factors underlying the intention to drink and drive in young male drivers. Journal of Safety Research, 32(4): 363-376.

Miller, M. B. 1995. Coefficient alpha: A basic introduction from the perspectives of classical test theory and structural equation modeling.

Mitra-Sarkar S, Andreas M. 2009. Driving behaviors, risk perceptions, and stress: An examination of military personnel during wartime deployment. Transportation research 
record. 2138(1): 42-45.

Mohamed M, Bromfield NF. 2017. Attitudes, driving behavior, and accident involvement among young male drivers in Saudi Arabia. Transportation Research Part F: Psychology and Behaviour, 47: 59-1.

Nordfjærn T, Rundmo T. 2009. Perceptions of traffic risk in an industrialised and a developing country. Transportation Research Part F: Traffic Psychology and Behaviour, 12(1): 91-98.

Nordfjærn T, Jørgensen S H, Rundmo T. 2010. An investigation of driver attitudes and behaviour in rural and urban areas in Norway. Safety science, 48(3): 348-356.

Nunnally J C. 1978.Psychometric Theory: 2d Ed. McGraw-Hill.

Rakha H, El-Shawarby I, Setti J R. 2007. Characterizing driver behavior on signalized intersection approaches at the onset of a yellow-phase trigger. IEEE Transactions on Intelligent Transportation Systems, 8(4): 630-640.

Romoser, M. R., Pollatsek, A., Fisher, D. L., Williams, C. C. 2013. Comparing the glance patterns of older versus younger experienced drivers: Scanning for hazards while approaching and entering the intersection. Transportation research part F: traffic psychology and behaviour, 16, 104-116.

Rowe R, Andrews E, 2016. Identifying beliefs underlying pre-drivers' intentions to take risks: An application of the Theory of Planned Behaviour. Accident Analysis and Prevention, 8949-56

Rundmo T, Iversen H. 2004. Risk perception and driving behaviour among adolescents in two Norwegian counties before and after a traffic safety campaign. Safety science, 42(1): 121.

Shladover, S. E. 2018. Connected and automated vehicle systems: Introduction and overview. Journal of Intelligent Transportation Systems, 22(3), 190-200.

Şimşekoğlu, Ö., Nordfjærn, T., Zavareh, M. F., Hezaveh, A. M., Mamdoohi, A. R., Rundmo, T. 2013. Risk perceptions, fatalism and driver behaviors in Turkey and Iran. Safety science, 59, 187-192.

Singh V., Sharma SK., 2014. Evolving base for the fuel consumption optimization in Indian air transport: Application of structural equation modeling. European Transport Research Review, 6(3): 315 - 332.

Singh V., Sharma SK., 2016. Analyzing the moderating effects of respondent type and experience on the fuel efficiency improvement in air transport using structural equation modeling. European Transport Research Review, 8(12): 1 - 20.

Sivak, M., Soler, J., Tränkle, U., Spagnhol, J. M. 1989. Cross-cultural differences in driver riskperception. Accident Analysis and Prevention, 21(4), 355-362.

Steinbakk, R. T., Ulleberg, Pål, Sagberg, F., Fostervold, K. I. 2019. Speed preferences in work zones: the combined effect of visible roadwork activity, personality traits, attitudes, risk perception and driving style. Transportation Research Part F: Traffic Psychology and Behaviour, 62, 390-405.

Takemoto, M., Kosaka, H., Nishitani, H. 2008. A Study on the Relationships between Unsafe Driving Behaviors and Driver's Inner Factors When Entering a Non-signalized Intersection. JCP, 3(9), 39-49.

Taubman-Ben-Ari, O., Kaplan, S., Lotan, T., Prato, C. G. 2016. The combined contribution of personality, family traits, and reckless driving intentions to young men's risky driving: 
What role does anger play? Transportation research part F: traffic psychology and behaviour, 42, 299-306.

Teo T, Milutinović V, Zhou M. 2016. Modelling Serbian pre-service teachers' attitudes towards computer use: A SEM and MIMIC approach. Computers and Education, 94: 77-88.

Tinsley H.E., Tinsley D.J., 1987. Uses of factor analysis in counseling psychology research. Journal of Counseling Psychology, 34, $414-424$.

Trond Nordfjrn, Torbjørn Rundmo. 2009. Perceptions of traffic risk in an industrialised and a developing country. Transportation Research Part F, 12, 91-98.

Varet F, Granié M A, Apostolidis T. 2018. The role of individualism, gender and situational factors on probabilities of committing offences in a French driver's sample. Transportation research part F: traffic psychology and behavior, 56: 293-305.

Wang J, Wang X. 2019.Structural equation modeling: Applications using Mplus. John Wiley and Sons.

Wang X, Xu L, Hao Y. 2019. What factors predict drivers' self-reported lane change violation behavior at urban intersections? A study in China. PLoS one, 14(5): e0216751.

Wang, J., Zhang, L., Zhang, D., Li, K. 2012. An adaptive longitudinal driving assistance system based on driver characteristics. IEEE Transactions on Intelligent Transportation Systems, 14(1), 1-12.

Whitlock, G., Norton, R., Clark, T., Pledger, M., Jackson, R., MacMahon, S. 2003. Motor vehicle driver injury and socioeconomic status: a cohort study with prospective and retrospective driver injuries. Journal of Epidemiology and Community Health, 57(7), 512-516.

Yang G, Gaweesh S, Ahmed M. 2019. Development and assessment of a connected vehicle training program for truck drivers. Transportation Research Board.

Yang H., 1., Liu X., H., Su F., Cherry C., Liu Y., Li Y., L. 2018. Predicting e-bike users' intention to run the red light: An application and extension of the theory of planned behavior. Transportation Research Part F: Traffic Psychology and Behaviour. 58, 282-291.

Yao, Z., Jiang, Y., Zhao, B., Luo, X., Peng, B. 2020. A dynamic optimization method for adaptive signal control in a connected vehicle environment. Journal of Intelligent Transportation Systems, 24(2), 184-200.

Yi, D., Su, J., Hu, L., Liu, C., Quddus, M. A., Dianati, M., Chen, W. H. 2019. Implicit personalization in driving assistance: State-of-the-art and open issues. IEEE Transactions on Intelligent Vehicles.

Zhou H, Romero S B, Qin X. 2016. An extension of the theory of planned behavior to predict pedestrians' violating crossing behavior using structural equation modeling. Accident Analysis and Prevention, 95: 417-424.

Zhou R, Horrey W J, Yu R. 2009.The effect of conformity tendency on pedestrians' roadcrossing intentions in China: An application of the theory of planned behavior. Accident Analysis and Prevention, 41(3): 491-497. 